The Geneva Papers on Risk and Insurance, 18 (No. 69, October 1993), 443-448

\title{
Large Industrial Risks, Catastrophes and Environmental Threats, Defining Insurability, the Role of Private Insurance Industry and the State
}

\author{
by Ernesto Jutzi*
}

\section{Introduction}

I shall focus my remarks on large industrial risks which clearly are the domain of the private insurance industry. There is a great need for action in this field resulting from persistent, unbounded competition and a continuously changing risk profile. I shall first make a few comments for your consideration and then condense my contribution into four key messages or theses to facilitate the transition to the following round of discussion.

\section{Global change in the risk environment}

Let me begin by taking a quick look at the early days of industrialisation. For instance, when the "Manchester Steam Users Association" was founded in 1854, boiler explosions were extremely feared. The problems were brought under control reasonably well in a pragmatic combination of legally prescribed controls and insurance coverage for property damage and personal injury as well as third-party liability claims.

Of course, industry has since then made large efforts to minimise risks and potential losses with measures such as improved construction methods, new technologies, improved security and monitoring equipment, better training, legal provisions, etc.

And yet mankind is being exposed to numerous previously unknown risks, hazards and catastrophe potentials brought about by booming industrial activity, by enormous resource and energy consumption and by the pollution of air, water and the environment in general through noxious material.

Moreover, cost/benefit considerations play a decisive role at the individual level and often impair the consistent enforcement of suitable measures. The criticism has also been voiced that the insurance industry actually facilitated a wide range of novel hazard potential either entirely or in part precisely through the financial protection it provides.

An additional aggravation or challenge stems from the fact that "risk" is a term of which every child, person, politician, entrepreneur, sociologist, engineer, economist or

* Head of the Executive Board of Swiss Re, Zurich. Paper presented at the 20th General Assembly of the Geneva Association, Vienna, June 7, 1993. 
business administrator generally has a different conception or definition and, more particularly, a different degree of acceptance. From the viewpoint of insurance, risk was long regarded as a commercial/mathematical value consisting of the multiplication of the probability and size of a loss. In the meantime, new and more comprehensive terms have emerged in large-scale industry and all areas in which new technologies are affecting people, society and the environment. These terms include:

1 Consequence out of uncertainty

2 Chance or loss

3 The possibility that interference processes prevent the financial expectations of an enterprise from being met.

The term "risk" is not merely a technical (industry) nor an exclusively financial issue (insurance). Risk concerns all of us. Ultimately, the crucial point is that an expectation which is presumed "plannable" actually contains a consequential element of uncertainty.

\section{Risk management}

Risk management with all its aspects - from perception via the targeted risk policy to the settlement of risks - has become a demanding process. What started out modestly in many places - e.g. as fire protection or factory inspections - has established itself as an integral aspect of business management supporting the realisation of set business objectives.

Of course, we cannot deny that the daily work of an industrial risk manager contains many unexpected turns; certain threats of loss potential have not even been guessed at entirely or in part. There is no lack of catchwords for underestimated occurrences!

I shall mention only asbestos fibre, mercury poisoning, breast implantations, repetitive strain injuries, seepage and pollution, mortgage loan business, Piper Alpha, Bhopal, terrorist attacks in the City of London or New York (World Trade Center).

Linear thinking, which used to be sufficient in risk management, has had to be replaced by a lateral approach. The worldwide interweaving of numerous economic branches, the international division of labour and new methods of production - CIM computer integrated manufacturing, lean production (i.e. general abandonment of stock and buffer inventories) - have drastically raised the susceptibility of the industry to interference. I might mention the underestimated risks inherent in reciprocal losses and customers' and suppliers' extension losses in connection with business interruption.

The principle of economies of scale is frequently the reason why the enormous concentration of values in factories, warehouses, etc. is underestimated. Parallel to this development, there has been a marked rise in the utilisation of flammable and toxic substances in production processes.

Instructions issued by the authorities in the event of imminent losses or after an occurrence are a tricky issue. The delayed resumption of production, the disposal of contaminated waste and thorough environmental compatibility tests often turn out to be very expensive indeed.

Concerning environmental risks, reference must be made to the role of the legislator and legal frame conditions which place a great challenge to the conduct and procedures of both industry and insurance in the future. 
In addition to technological uncertainty and tightening legal liability or technical standards, social pressures also wield a remarkable influence in environmental concerns.

It currently does appear as though the private insurance industry was able to get to terms with the problems emerging from environmental impairment. Nevertheless, a reorientation of the role of insurance to this area seems absolutely indispensable, particularly in view of the experiences made with residual pollution loads in the United States. Here, the casting of parts between the State and the private sector appears to be a plausible solution.

Risks in product liability are difficult to assess. Legal liability extensions such as the planned transition from negligence liability to strict liability, gradual pollution, damage series, uncertainty in the choice of the place of jurisdiction, endless discussions on trigger, claims made, occurrence or manifestation - all these aspects are disconcerting even for the most skilled specialist - if not in risk management or underwriting, then certainly with regard to loss occurrences involving liability disputes.

The ability to distinguish the significant from the trivial, to set the right priorities, to condense and express the flood of information in a nutshell or as a set of keywords - all these aspects make risk management in the field of large-scale industry a fascinating and yet very difficult task. Finally, the results must also be communicated. The work results of teams consisting of specialists from different disciplines need to be prepared for a great many different addressees - from the customer to the underwriter - in a manner which ensures that everyone understands them. We must intensify the risk dialogue at all levels!

\section{Business protection and risk financing}

A strong wind of change has come up in the insurance industry. Structural change has partially arisen out of the departure from market regulating principles which had previously been quite strictly observed, out of an altered buying behaviour and not least out of careless underwriting which manifested itself, for instance, in innocent capacity or cashflow underwriting.

An accelerated positioning by customer segment is emerging on the supply side. These segments consist of mass business, personal lines, medium-sized and large-scale industry (multinational companies).

A growing number of members in the last group are establishing their own captive companies also in Europe.

New customer requirements are evolving in large-scale industry - away from the rigid division by line of business towards a more comprehensive approach - resulting in what is termed business protection.

This new feature comprises the activity of top management dealing with potential disruptions and impairments jeopardizing predetermined corporate goals.

The main emphasis is placed on the following four areas:

- property (physical goods, e.g. buildings, machinery, etc.)

- income flow and financial impairments (liquidity, squeeze, bankruptcy, etc.)

- third party liability

— persons (life, health, accident). 
There is not enough time for me to deal with this issue in any detail, but I would like you to note that business protection concerns both insurable and non-insurable occurrences.

Of course, the borders of insurability in industrial business are fluid; they depend on markets, customers, Zeitgeist, professionals in insurance, etc.

Business protection is complemented by risk financing defined as comprising the sum of all costs/expenses required for corporate asset protection.

A good many questions could now be asked with regard to the technical aspects of insurance. Let me just mention two:

1 pricing

2 capacity

Pricing: There are many reasons to explain why, in industrial business, the calculation of premiums tailored to the corresponding risk has become implausible. These include the formation of risk categories - who is being solidary with whom; at all events, lateral subsidizing is a thing of the past - the inadequate volume of statistical samples - the law of large numbers no longer works smoothly and requires substantial fluctuation surcharges - etc. The controversy is heightened with the credibility theory - which was developed by Bühlmann, Straub - particularly with regard to the optimum trimming and redistribution of loss burdens to other types of risk. A statement from the risk manager of a major European group is right to the point: We invest billions of ECU's into security and preventive loss reduction. Our loss burden is modest and we are no longer prepared to contribute towards the high loss burdens of certain industrial branches.

We should also keep in mind the high costs and commissions which are deducted from the actual risk premium. Moreover, the level of training of many "underwriters" leaves much to be desired. Unfortunately, we appear to be witnessing a general dwindling of intellectual agility coupled with experience and intuition, flexible persistence, a sense of proportion and prudent risk aversion arising from the very nature of the profession. Short-term profit embellishments by way of premium reductions have had fatal effects. I personally advocate long-term cooperation based on confidence and trust: it is the only option for respectable suppliers to establish and maintain the essential balance in time and space.

The risk of change also plays a part. Coverage commitments which do not reach maturity until some date in the distant future very rarely allow us to extrapolate from past experience to the future. Often the quality of risk data bases is insufficient. This affects, for example, the difficult issue of granting appropriate rebates on deductibles and loss limits.

We are dealing with a great many problems which are not likely to be solved with market premiums. At all events, the insurance industry is well advised to utilise the discretionary scope it has been granted in the Group exemption regulation of Brussels instead of pretending cartel handicaps.

Capacity: Is capacity a commodity - i.e. a common resource - or an asset to be utilized with the utmost care? I am convinced that the current general malaise was aggravated by an over-generous granting of capacity under reinsurance contracts. An essential task will be to eliminate innocent capacity and have reinsurers formulate tangible definitions and exclusions, for example in the following manner: 
- Captive reinsurance requires a professional leader who has a decisive say in the conditions of acceptance, rating, claims handling, etc.

- Captive reinsurance capacity must be limited, the yardstick being the fluctuation potential of incoming business. Capacity and premium volume must be harmonised in line with recognised rules.

- The placement of a risk must be transparent. The underwriting reinsurer must be familiar with all gross and net amounts.

- Each captive carries an appropriate share of the risk itself and plans its contracts over a long period.

Other decisive features of security - in addition to net capacity and price - include financial strength, continuity, i.e. long-term business relations and, last but not least, the expertise of the supplier. More to the point, industrial risks need a motivated, committed and competent leader who is also capable of providing the necessary transparency. Insurers and reinsurers alike must no longer be allowed to take the lead for major risks if they do not possess the required competence in terms of staff, finance or professional skill.

Precisely what are the issues I have been addressing before?

a) Armoured as it is with vast experience in dealing with risk, the insurance industry cannot be persuaded out of its conviction that the problems posed by a constantly changing risk environment can be settled with a range of tried and tested methods. At the same time, it is being challenged to actively follow unconventional paths, to find solutions, to absorb external incentives in a positive approach and turn them into concrete forms, such as a constructive approach to captives, unbundled programmes, financing alternatives and other solutions.

Many healthy principles were sacrified in the interest of innovative change during the euphoric boom period of the eighties and in the wake of profitable financial operations which bore the distinct features on an unrestrained will for modernisation.

Our task must be to refer back to the basis of insurance and pursue our profession with a commitment to profitability. Whatever approach we ultimately select, professional expertise will always be a requisite.

b) Competition in the insurance of local and, more particularly, of multinational industrial risks must not be based only on the usual market price. A sound and technically wellfounded risk analysis must precede any risk transfer. Of course, the effort involved here depends on the complexity of the enterprise as a whole and does not end when the contract is signed. Tasks to perform during the coverage period include closely watching any changes of the risk, introducing risk reducing measures and adjusting design and premium calculation of the insurance programme.

Risk engineers and underwriters must be considered equal partners, and their professional skills must be combined. Working in close cooperation, they should establish and secure a comprehensive risk profile constituting the essential basis for the provision of insurance coverage.

Insurance companies which do not have the necessary technical equipment or fail to apply it consistently should not be allowed to take on the leading function in major 
insurance programmes. Reinsurers can effectively prevent this from occurring by excluding peak risks from automatic coverage and referring to the facultative option instead.

c) We need not dwell on the fact that prices for insurance services (i.e. risk handling and risk transfer) are still too low in industrial business. In general, the situation is at its most acute in property insurance, although there is also considerable loss potential in liability insurance due to the long-term effects of certain hazards and the continuous risk of change. These unfavourable conditions are dominant today, in a period of deregulation and opening markets. It is of vital importance for the future of our economic sector that the regulatory forces of each individual market are not entirely overrun by the globalisation process which is brought on by competition.

Unlike mass business, the store of experience in industrial business is not based on sufficient statistical data. The relevant values with which both insurance and reinsurance are being increasingly confronted here are first the growing severity of a probable loss and only then the frequency of a loss.

In passing the group exemption clause on 31 May 1991, the EC Commission recognized the necessity for special regulations on the common assessment of risk premiums. The insurance industry is well advised to make deliberate use of the granted scope of discretion despite the general decartelisation trend.

d) In connection with the premise I have just mentioned, I should also refer to the efficiency coefficient which most insurance buyers consider too low, to the effect that they are constantly seeking alternative solutions. The customers regard insurance as a cost factor which ought to be brought down. Therefore, if in a premium calculation almost half the amount is accorded to acquisition and management costs, this relation should at least be explained. The improvement of efficiency should not show merely in a better cost structure but also in effective risk management.

One concern which encompasses all the premises I have presented is what Professor $\mathbf{M}$. Haller of the University of St. Gall terms risk dialogue - meaning an open, spontaneous and also organised form of communication between insurers and insured parties, the public at large, politics, economics and science.

The lack of confidence shown in the insurance industry may well stem from the fact that insurers are often taken to the limits of what is possible and are faced with consequences which they did not help to create in the first place. We must make up for this handicap by improving communication.

We have recently spent a lot of time talking about shrinking or even disappearing capacity, and are concerned by what we see. The phenomenon presenting itself to us has resulted from a great many reasons, including meteorological, legal, social and other aspects, but also - and not least - errors and lethargic behaviour of the insurance and reinsurance industry.

The availability of capacity will in the future depend heavily on our willingness to take steps to do the right things in time, instead of reacting in the aftermath of adverse experience. When I say "capacity", I mean real, responsible capacity that will be around if tested in one, two or more years' time. 